\title{
A novel antimicrobial peptide significantly enhances acid-induced killing of Shiga toxin-producing Escherichia coli $\mathrm{O} 157$ and non-O157 serotypes

\begin{abstract}
Correspondence
D. Barnett Foster
\end{abstract} \\ dfoster@ryerson.ca \\ Received 22 December 2010 \\ Revised 17 March 2011 \\ Accepted 24 March 2011

\author{
M. Lino, ${ }^{1}$ J. V. Kus, ${ }^{1}$ S. L. Tran, ${ }^{1}$ Z. Naqvi, ${ }^{1}$ B. Binnington, ${ }^{2}$ S. D. Goodman, ${ }^{3}$ \\ A. M. Segall ${ }^{4}$ and D. Barnett Foster ${ }^{1,2}$ \\ ${ }^{1}$ Department of Chemistry and Biology, Ryerson University, Toronto, ON, Canada \\ ${ }^{2}$ Molecular Structure and Function, Hospital for Sick Children, Toronto, ON, Canada \\ ${ }^{3}$ Division of Biomedical Sciences, Herman Ostrow School of Dentistry of the University of Southern \\ California, USA \\ ${ }^{4}$ Department of Biology, Center for Microbial Sciences and Molecular Biology Institute, \\ San Diego State University, USA
}

\begin{abstract}
Shiga toxin-producing Escherichia coli (STEC) colonizes the human intestine, causing haemorrhagic colitis and haemolytic uraemic syndrome (HUS). Treatment options are limited to intravenous fluids in part because sublethal doses of some antibiotics have been shown to stimulate increased toxin release and enhance the risk of progression to HUS. Preventative antimicrobial agents, especially those that build on the natural antimicrobial action of the host defence, may provide a better option. In order to survive the acid stress of gastric passage, STEC is equipped with numerous acid resistance and DNA repair mechanisms. Inhibition of acid-induced DNA repair may offer a strategy to target survival of ingested STEC. We report here that brief pretreatment with a novel antimicrobial peptide, which was previously shown to inhibit bacterial DNA repair, significantly and profoundly reduces survival of acid-stressed O157:H7 and non-O157 : H7 STEC seropathotypes that are highly associated with HUS. Reduction in survival rates of STEC range from 3 to 5 log. We also show that peptide/acid treatment results in little or no increase in toxin production, thereby reducing the risk of progression to HUS. This study identifies the peptide wrwycr as a potential new candidate for a preventative antimicrobial for STEC infection.
\end{abstract}

\section{INTRODUCTION}

Shiga toxin-producing Escherichia coli (STEC) is a serious food- and water-borne pathogen that causes a variety of illnesses ranging from mild diarrhoea to severe, bloody diarrhoea (haemorrhagic colitis), and life-threatening systemic sequelae including haemolytic uraemic syndrome (HUS) (Karmali, 2004; Nataro \& Kaper, 1998). The development of systemic complications is attributed to the production of prophage-encoded Shiga toxins (Karmali, 2004; Scheiring et al., 2008). Although the serotype O157:H7 is most highly associated with outbreaks and severe disease (including HUS) in North America, the non-O157 serotypes also constitute a serious public health threat and are reported to be associated with as many as $20 \%$ of North American HUS cases (Banatvala et al., 2001; Karmali et al., 2003). The non-O157 serotypes

Abbreviations: HJ, Holliday junction; HUS, haemolytic uraemic syndrome; STx, Shiga-like toxin; STEC, Shiga toxin-producing Escherichia coli. have also been frequently associated with HUS, particularly in Latin America, Australia and Europe, and at least 200 strains of these serotypes have now been associated with human disease (Karmali et al., 2003). Recent evidence suggests that many of the non-O157:H7 strains have acquired additional virulence factors that correlate with outbreak and HUS potential in humans (Coombes et al., 2008). The World Health Organization has identified the virulent non-O157 STEC as a public health priority (Coombes et al., 2008). These results provide persuasive evidence of the need for prevention strategies that are equally effective against both $\mathrm{O} 157$ and non-O157 STEC strains.

Currently, there is no specific therapeutic treatment for STEC infection other than intravenous fluids (Ake et al., 2005; Palermo et al., 2009; Tarr et al., 2005; Bavaro, 2009). Doctors strongly advise against treatment with antibiotics, nonsteroidal anti-inflammatory agents or anti-motility agents, in part because studies have shown that sublethal 
antibiotic doses may stimulate STEC toxin production and promote the development of HUS in STEC-infected individuals (Scheiring et al., 2008). Consequently, research aimed at preventing the establishment of the primary infection may offer the best strategy for preventing STECassociated illness.

STEC, like all enteric pathogens, must survive exposure to the extreme acidity associated with gastric passage. STEC is well equipped with a variety of acid resistance mechanisms as well as repair mechanisms to combat acid-induced DNA damage (Foster, 2004; Lin et al., 1996). Exposure to low pH results in extensive depurination of DNA which, if not repaired, can have lethal consequences for the pathogen (Kunkel, 1984). Holliday junctions (HJs) and stalled replication forks are DNA structures that are central to DNA damage repair. Failure to resolve these intermediates can seriously compromise bacterial viability (Cox et al., 2000; Kuzminov, 1999; Michel et al., 2007). Therefore, inhibition of acid-induced DNA repair should enhance acid killing of STEC and may provide a novel antimicrobial strategy for preventing STEC infection.

Segall and colleagues have identified several peptides that prevent resolution of $\mathrm{HJ}$ intermediates by trapping the protein-bound HJ intermediate (Boldt et al., 2004; Cassell et al., 2000). Among the best characterized of these is the Damino acid hexapeptide wrwycr. This peptide binds HJs and other branched DNA intermediates, the latter with lesser affinity and stability, and by doing so, is able to inhibit a number of $\mathrm{HJ}$ processing enzymes in a structureselective manner (Kepple et al., 2005, 2008). During sitespecific recombination mediated by bacteriophage lambda integrase, an $\mathrm{HJ}$ intermediate is generated after the first round of DNA cleavage, strand exchange and ligation, and is resolved in a second round of the same catalytic steps (Azaro \& Landy, 2002). Peptide wrwycr prevents the resolution of the $\mathrm{HJ}$ intermediates to either products or substrates (Boldt et al., 2004).

Peptide wrwycr, when oxidized, functions as a disulfidelinked homodimer and is relatively hydrophobic (Boldt et al., 2004), thereby enhancing its passage through both the lipid bilayer membrane as well as the peptidoglycan layer in order to access HJ. It is composed of D-amino acids, which renders it resistant to in vivo peptidase degradation. The peptide WRWYCR, with the same sequence but composed of Lamino acids, interacts with $\mathrm{HJ}$ s with a $K_{\mathrm{d}}$ of $14 \mathrm{nM}$, inhibits several $\mathrm{HJ}$ resolution enzymes with an $\mathrm{IC}_{50}$ of 5-64 $\mathrm{nM}$ and is also bactericidal against non-pathogenic E. coli, although it is less antimicrobial than wrwycr (Gunderson \& Segall, 2006; Kepple et al., 2005, 2008). The peptide wrwycr has also been shown to inhibit Salmonella enterica growing inside murine macrophages (Su et al., 2010) and to have antimicrobial activity against non-pathogenic E. coli (Gunderson \& Segall, 2006). Importantly, wrwycr was found to have no toxic effect on J774A.1 macrophage-like cells and murine peritoneal macrophages in the study by $\mathrm{Su}$ et al. (2010).
In the current study, we hypothesized that if the lethal effects of DNA lesions due to low $\mathrm{pH}$ in the stomach could be enhanced by pretreatment with the peptide wrwycr, we could target killing of newly ingested STEC without damaging the beneficial commensal flora of the gut. This strategy could be used to develop an antimicrobial which could be applied to potentially contaminated foods prior to ingestion so as to enhance the killing effect of gastric acid stress. The goals of this study included: firstly, to determine if pretreating STEC with peptide wrwycr influences bacterial survival after acute acid stress; secondly, to examine the impact of treatment conditions including temperature, wrwycr concentration and acid exposure time on STEC survival; and finally, to evaluate the impact of wrwycr/acid treatment on Shiga toxin production. The study includes STEC strains representative of each of the O157:H7 and non-O157:H7 seropathotypes highly associated with human disease (Karmali et al., 2003). The findings provide the first evidence that wrwycr in combination with exposure to acid, similar to that typically encountered during ingestion, significantly and dramatically reduces survival of STEC strains of seropathotypes most highly associated with HUS without a concomitant increase in Shiga toxin production. Accordingly, wrwycr could serve as an antimicrobial agent for prevention of STEC-induced food-borne illness.

\section{METHODS}

Bacterial strains and growth conditions. Seven STEC strains (Table 1), kindly provided by Dr Karmali, Public Health Agency of Canada, were used in this study. Karmali et al. (2003) classified STEC based on the relative frequency with which each of the serotypes is associated with serious and epidemic human disease. A summary of the strains used in this study, their STEC seropathotypes and their association with outbreaks of human disease and development of severe disease (HUS) is provided in Table 1. Bacteria were maintained as glycerol stocks at $-80{ }^{\circ} \mathrm{C}$. Prior to use, bacteria were streaked for single colonies on LB agar. Single colonies were used to inoculate LB broth for overnight culture at $37{ }^{\circ} \mathrm{C}$ with shaking. Fresh cultures from glycerol stocks were prepared for each individual experiment in order to maintain the original clinical characteristics of the stock. Bacterial viability was assessed by serial dilution and plating on LB agar.

Synthesis of wrwycr. The peptide wrwycr was synthesized with a Cterminal amide group, purified to $>95 \%$ purity at Sigma-Genosys or Biosynthesis and dissolved in 50\% DMSO as described previously (Gunderson \& Segall, 2006). A wrwycr stock solution (10 mM) was maintained in 50 or $100 \%$ DMSO. Final DMSO concentrations were either 0.5 or $1.0 \%$ and DMSO at an appropriate concentration was added in the absence of wrwycr to control for DMSO effects.

Survival assays. Overnight LB broth cultures were diluted 1:6 in LB broth and grown to mid-exponential phase $\left(\mathrm{OD}_{600} 0.4-0.6\right)$. For acid stress survival studies, bacteria were pelleted, resuspended in LB either pH 7.0 or $\mathrm{pH} 2.5$ (adjusted with $\mathrm{HCl}$ ). The first sample taken immediately after bacteria were resuspended was designated time 0 ; sampling and plating were done four times for a total of $3 \mathrm{~h}$ incubation. Bacterial viability was assessed by serial dilution and plating on LB agar.

For the peptide/acid treatment survival studies, bacterial pellets as above were resuspended in either $0.5 \times \mathrm{PBS}$ at $\mathrm{pH} 7.0$, or $0.5 \times \mathrm{PBS}$ 
Table 1. Description of strains used in this study

NA, Not applicable. All data (except for MG1655) are taken from Karmali et al. (2003).

\begin{tabular}{|lcccc|}
\hline Strain & Serotype & Shiga-like toxin (STx) production & Relative incidence/association with HUS & Seropathotype group \\
\hline $86-24$ & O157:H7 & STx2 & High/yes & A \\
D103F5 & O157:H7 & STx1, STx2 & High/yes & A \\
CL1 & O26:H11 & STx1 & Moderate/yes & B \\
CL106 & O121:H19 & STx2 & Loderate/yes & B \\
N99-4390 & O121:NM & STx1, STx2 & C \\
EC2-211 & O113:NM & STx2 & Non-human & E \\
MG1655 & K-12 & NA & NA & \\
\hline
\end{tabular}

and wrwycr (concentrations ranging from 25 to $75 \mu \mathrm{M}$ ) at $\mathrm{pH}$ 7.0. The first sample, immediately following suspension in PBS, was serially diluted, plated and was designated 'unstressed'. Bacteria were incubated with wrwycr at room temperature, $30{ }^{\circ} \mathrm{C}$ or $37{ }^{\circ} \mathrm{C}$ for 5 min, after which the suspensions were acidified to $\mathrm{pH} 2.5$ by the addition of $0.5 \times$ PBS $\mathrm{pH} 1.2$. The second sample immediately following wrwycr treatment was serially diluted, plated and designated time 0 . Subsequent samples were obtained for $15,30,60$ and $120 \mathrm{~min}$ at $\mathrm{pH} 2.5$ and room temperature, $30{ }^{\circ} \mathrm{C}$ or $37^{\circ} \mathrm{C}$. Viability was assessed by serial dilution and plating on LB agar. Earlier studies had identified $25 \mu \mathrm{M}$ wrwycr as the lowest effective dose for enhanced acid-induced killing of non-pathogenic E. coli and we tested concentrations ranging from 25 to $75 \mu \mathrm{M}$ wrwycr in our assays with STEC.

Shiga toxin production. The effect of peptide treatment on Shigalike toxin $(\mathrm{STx})$ production was measured using a Vero cell cytotoxicity assay as described previously (House et al., 2009). Purified stock solutions of STx1 and STx2 $\left(100 \mu \mathrm{g} \mathrm{ml}^{-1}\right)$ were kindly provided by Dr Lingwood, Hospital for Sick Children, Toronto, ON, Canada. Vero cells (ATCC) were cultured at $37{ }^{\circ} \mathrm{C}, 5 \% \mathrm{CO}_{2}$ in complete medium (minimal essential medium supplemented with $5 \%$ fetal bovine serum, $100 \mathrm{IU}$ penicillin $\mathrm{ml}^{-1}, 100 \mu \mathrm{g}$ streptomycin $\mathrm{ml}^{-1}$ ). For the cytotoxicity assay, cells were seeded at 20000 cells in $200 \mu \mathrm{l}$ per well in 96-well plates and cultured overnight to form a monolayer. Serial dilutions of purified STx1, STx2 or STx extracts from STEC strains (described below) were prepared in triplicate in complete medium and $50 \mu \mathrm{l}$ was added per well. The plates were incubated for $72 \mathrm{~h}$ after which viable, adherent cells were fixed with $2 \%$ formaldehyde and stained with crystal violet as described by Gentry \& Dalrymple (1980). Crystal violet staining was quantified by absorbance at $570 \mathrm{~nm}$ after solubilization of the dye with $100 \mu \mathrm{l}$ per well of $10 \%$ acetic acid in water.

Shiga-like toxin extracts were isolated as described previously (House et al., 2009). Briefly, overnight cultures of representative strains of each seropathovar were grown in LB broth, then subcultured in LB at $37{ }^{\circ} \mathrm{C}$ with shaking until mid-exponential phase. Bacteria were spun down and resuspended in $0.5 \times \mathrm{PBS}, \mathrm{pH} 7.0$, with or without $25 \mu \mathrm{M}$ wrwycr at room temperature for $5 \mathrm{~min}$. The bacterial suspension was adjusted to $\mathrm{pH} 2.5 \mathrm{using} \mathrm{HCl}$ then incubated at room temperature for $10 \mathrm{~min}$. Each sample was then subcultured into Penassay broth and incubated overnight (at $37{ }^{\circ} \mathrm{C}$ with shaking). Bacteria were pelleted by centrifugation, and the supernatants (secreted STx) were filter-sterilized and stored at $-20{ }^{\circ} \mathrm{C}$. Periplasmic STx extracts were isolated by resuspending bacterial pellets in polymyxin $\mathrm{B}\left(0.1 \mathrm{mg} \mathrm{ml} \mathrm{m}^{-1}\right.$; Sigma $)$, which disrupts the outer membrane and releases the periplasmic contents, and incubating statically at $37^{\circ} \mathrm{C}$ for $30 \mathrm{~min}$ (Karmali et al., 1985). After centrifugation, the periplasmic extracts were filter-sterilized and stored at $-20{ }^{\circ} \mathrm{C}$ prior to use.
Statistical analysis. Results are expressed as means \pm SD. Friedman two-way analysis of variance and Kruskal-Wallis one-way analysis of variance were used for statistical analysis of intergroup comparisons. Pairwise $t$-tests were performed for paired data. $P \leqslant 0.05$ (confidence interval of $95 \%$ ) was considered significant.

\section{RESULTS}

\section{Survival of STEC seropathotypes after acid stress}

All the O157 and non-O157 STEC strains used in this study showed a significant decrease in viability after $3 \mathrm{~h}$ in pH 2.5 LB broth (Fig. 1). For the two O157:H7 strains tested, there was a $3 \log$ decrease in survival after $3 \mathrm{~h}$ exposure to pH 2.5 (strain 86-24, Fig. 1a; strain D103F5, not shown). Similarly, all of the non-O157 strains tested showed a significant loss of viability after acid stress with varying degrees of sensitivity. Strains from seropathotype B showed survival losses at $\mathrm{pH} 2.5$ ranging from a 2 log decrease over $3 \mathrm{~h}$ (CL106, Fig. 1b) to a 3-5 log decrease after $1 \mathrm{~h}$ (CL1, data not shown). Seropathotype C strain N99-4390 was particularly sensitive to acid, with no detectable survival after $2 \mathrm{~h}$ at $\mathrm{pH} 2.5$ (Fig. 1c). The nonpathogenic strain MG1655 showed a 3 log loss after $3 \mathrm{~h}$ exposure to acid stress with a plot similar to Fig. 1(a) (data not shown). The non-human, non-pathogenic strain EC2211 showed a $2 \log$ loss over $3 \mathrm{~h}$ (Fig. 1d), in a manner similar to pathogenic strain CL106 (Fig. 1b). These results clearly establish that the STEC seropathotypes, like nonpathogenic E. coli, are sensitive to acid to varying degrees and more importantly, they provide a baseline against which to compare the impact of peptide on acid sensitivity of these seropathotypes.

\section{Peptide treatment significantly augments acid-induced killing of STEC $0157:$ H7}

In our initial experiments with wrwycr/acid treatment, we examined the effect of various incubation temperatures, times and peptide concentrations using the O157:H7 strains, 86-24 (Fig. 2) and D103F5 (not shown). When STEC O157: $\mathrm{H} 7$ was incubated with $25 \mu \mathrm{M}$ wrwycr at room temperature for $5 \mathrm{~min}$ followed by room temperature incubation at $\mathrm{pH} 2.5$, bacterial survival was significantly 

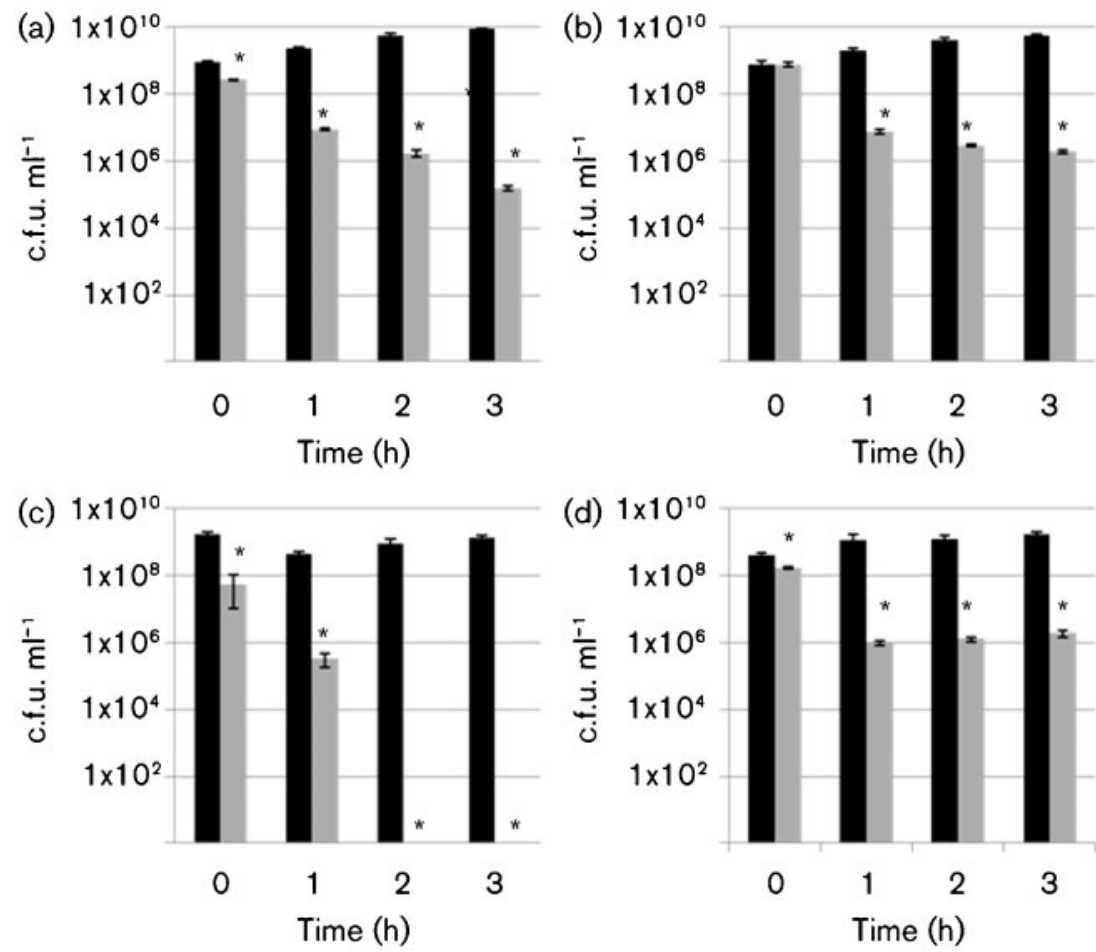

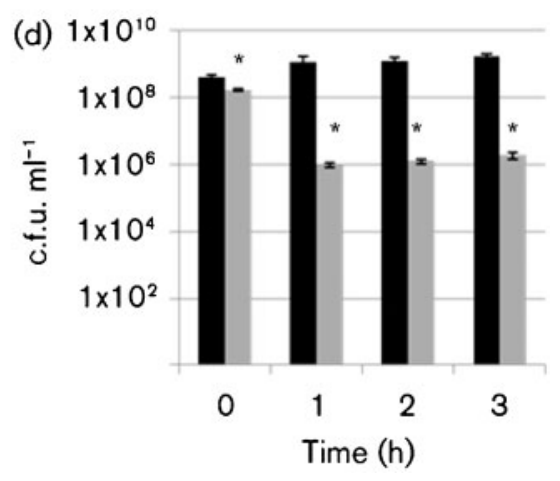

Fig. 1. Survival after acid stress. Survival of strains 86-24 (a), CL106 (b), N99-4390 (c) and EC2-211 (d) after incubation in LB at $37{ }^{\circ} \mathrm{C}$ at either $\mathrm{pH} 7.0$ (black bars) or $\mathrm{pH} 2.5$ (grey bars). Each experiment includes two biological replicates and three technical replicates. Asterisks indicate a statistically significant difference relative to the corresponding control, confidence interval $95 \%$. Error bars indicate SD.
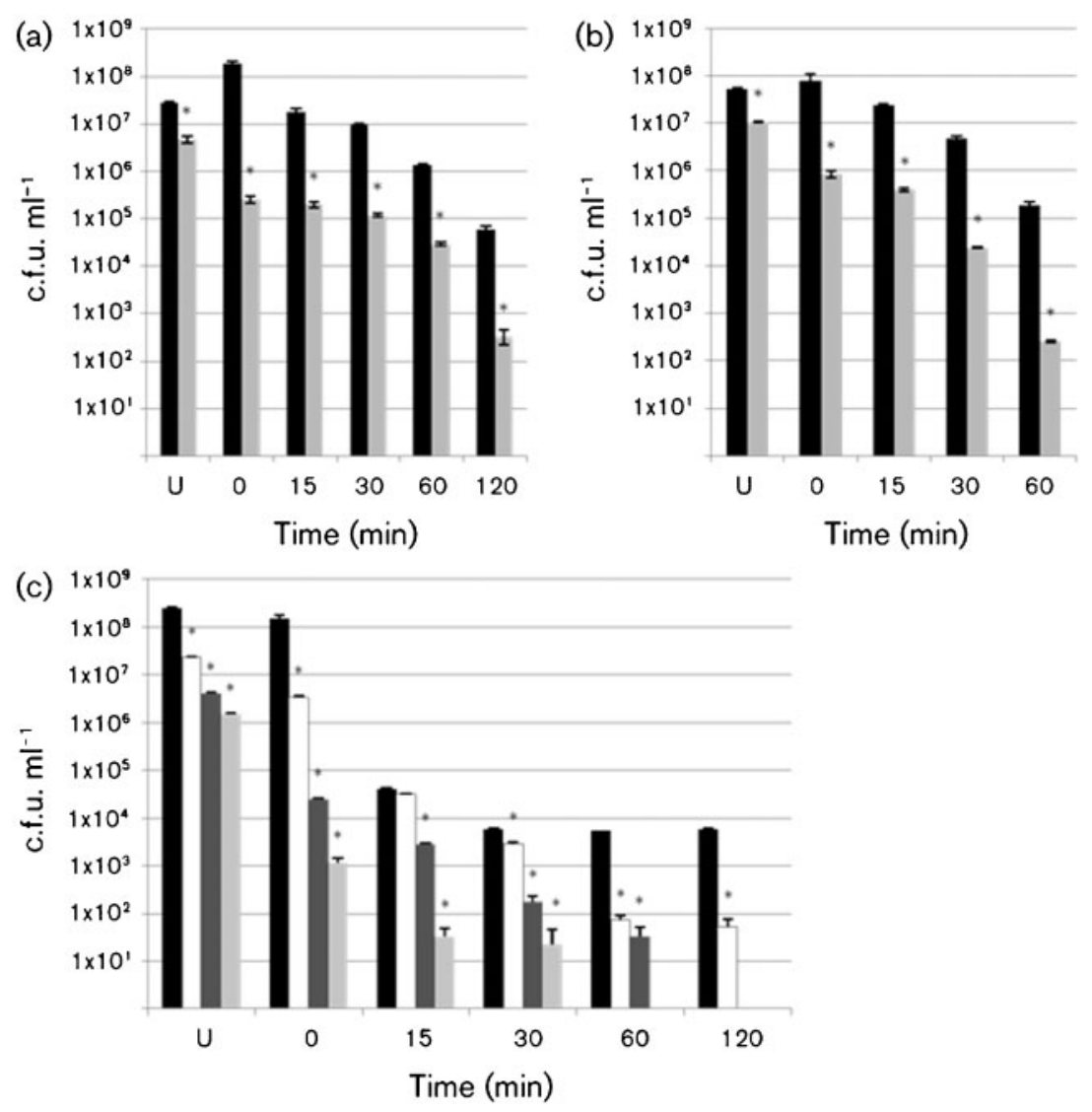

Fig. 2. Peptide wrwycr/acid treatment. The impact of temperature, time and peptide concentration on survival of STEC strain 86-24 after 5 min incubation with PBS (black bars), $25 \mu \mathrm{M}$ wrwycr (grey bars), $50 \mu \mathrm{M}$ wrwycr (dark-grey bars, c only) or $75 \mu \mathrm{M}$ wrwycr (white bars, c only) followed by timed acid stress exposure. Both wrwycr and acid stress incubations were conducted at room temperature (a), $30{ }^{\circ} \mathrm{C}(\mathrm{b})$ or $37{ }^{\circ} \mathrm{C}$ (c). Asterisks indicate a peptide treatment with a statistically significant difference relative to untreated control, confidence interval $95 \%$. U, Unstressed. Error bars indicate SD. 
decreased over the total $2 \mathrm{~h}$ period and, at each time interval, there was a $2-3 \log$ decrease in viability of the wrwycr/acid-treated samples relative to non-wrwycr/acidtreated samples. Similar results were observed when $25 \mu \mathrm{M}$ wrwycr and acid treatments were both conducted at either $30{ }^{\circ} \mathrm{C}$ (Fig. 2b) or $37^{\circ} \mathrm{C}$ (Fig. 2c). Fig. 2(c) also demonstrates a significant dose-dependent increase in peptide/acid killing of STEC O157: $\mathrm{H} 7$ using wrwycr concentrations ranging from 0 to $75 \mu \mathrm{M}$. Survival was increasingly compromised with increasing concentrations of peptide, with no survival detected with $50 \mu \mathrm{M}$ wrwycr coupled with $120 \mathrm{~min}$ of acid stress or $75 \mu \mathrm{M}$ wrwycr coupled with just $60 \mathrm{~min}$ of acid stress.

Finally, since the peptide treatment could serve as a preingestion intervention strategy (i.e. the pathogen is exposed to the peptide prior to ingestion), we also wanted to test the effect of wrwycr incubation at room temperature followed by a $37{ }^{\circ} \mathrm{C}$ acid stress, the latter part of which would be typically encountered during gastric passage. When a 5 min room temperature incubation with $25 \mu \mathrm{M}$ wrwycr was followed by a $37^{\circ} \mathrm{C}$ incubation at $\mathrm{pH} 2.5$, survival of the wrwycr/acid-treated samples relative to the non-wrwycr/acid-treated samples was dramatically decreased (Fig. 3a). Since these conditions provided the most pronounced antimicrobial effect at the lowest concentration of wywycr tested, they were selected for the subsequent survival experiments with the different seropathotypes.

\section{Peptide treatment significantly enhances acid- induced killing of non-0157: H7 STEC}

Using these conditions, we determined that wrwycr pretreatment significantly reduces the survival of acidstressed samples relative to untreated acid-stressed samples of STEC seropathotypes A, B and C, all of which are highly associated with outbreaks and severe human disease (Fig. 3 ). Both strains from seropathotype A (D103F5 and 86-24) were significantly more sensitive to the acid after exposure to wrwycr, with no detectable survival after $1 \mathrm{~h}$ of wrwycr/ acid treatment (86-24, Fig. 3a; D103F5, not shown). Strains from seropathotypes $\mathrm{B}$ and $\mathrm{C}$ were even more sensitive to wrwycr/acid treatment with CL1 (seropathotype B), CL106 (seropathotype B) and N99-4390 (seropathotype C) showing no detectable survival after 15, 30 and $30 \mathrm{~min}$, respectively, of wrwycr/acid treatment (CL106, Fig. 3b; CL1, not shown; N99-4390, Fig. 3c). The non-pathogenic strain EC2-211 of seropathotype E (of bovine origin and
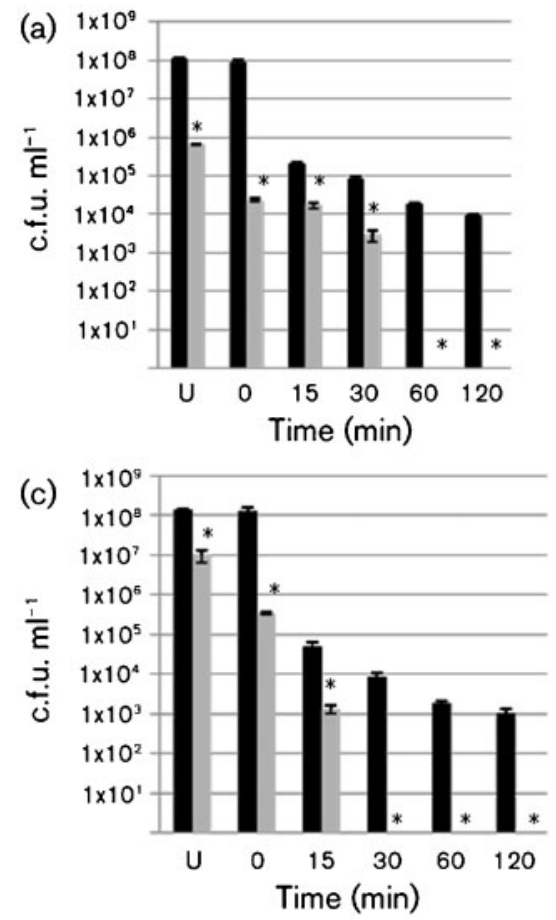

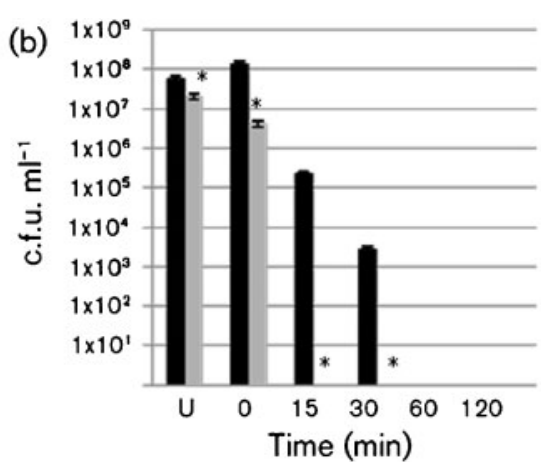

(d)

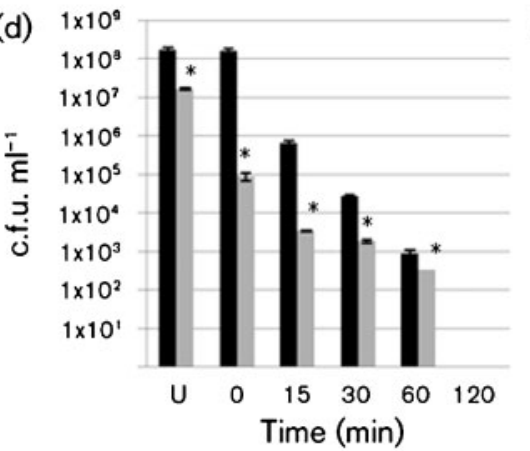

(e)

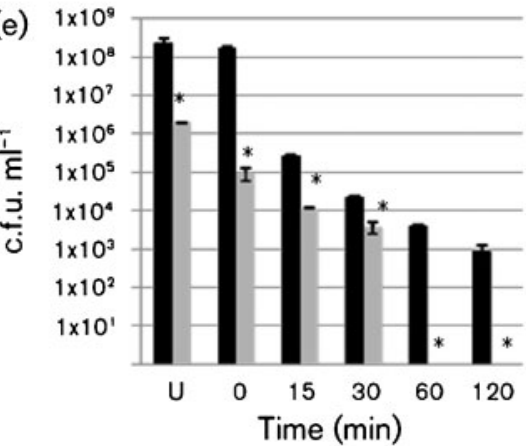

Fig. 3. Comparison of survival of $\mathrm{O} 157$ and non-O157 strains after peptide/acid treatment. Survival after incubation with wrwycr for $5 \mathrm{~min}$ at room temperature followed by timed $37{ }^{\circ} \mathrm{C}$ acid stress exposure. Survival of control [incubation in PBS followed by $\mathrm{pH} 2.5$ treatment (black bars)] or sample [incubation in $25 \mu \mathrm{M}$ wrwycr in PBS followed by pH 2.5 treatment (grey bars)] of strain 86-24 (seropathotype A) (a), strain CL106 (seropathotype B) (b), strain N99-4390 (seropathotype C) (c), strain EC2-211 (seropathotype E) (d) or MG1655 (e). Each experiment includes two biological replicates and three technical replicates. Asterisks indicate a statistically significant difference relative to the corresponding control, confidence interval $95 \%$. U, Unstressed. Error bars indicate SD. 
not associated with human disease) showed a significant $5 \log$ decrease in survival after $1 \mathrm{~h}$ wrwycr/acid treatment with modest but significant survival decreases relative to the acid/treatment alone (Fig. 3d). Finally, wrwycr/acid treatment of the non-pathogenic E. coli strain MG1655 significantly reduced survival relative to the untreated, acid-stressed sample, with a $3 \log$ reduction in viability within $30 \mathrm{~min}$ and no viable bacteria detected at $1 \mathrm{~h}$ (Fig. $3 e)$. This behaviour was similar to that of strains from seropathotype A.

We note that the detection limit of this assay is $50-100$ c.f.u. $\mathrm{ml}^{-1}$ which could still represent an infectious dose of STEC. However, the results clearly indicate dramatic and significant survival loss for all of the STEC pathogenic strains, decreasing from $10^{8}$ c.f.u. $\mathrm{ml}^{-1}$ to below the detection limit of 50-100 c.f.u. $\mathrm{ml}^{-1}$ after a 5 min wrwycr treatment followed by $15-60 \mathrm{~min}$ at $\mathrm{pH} 2.5$ (Fig. 3a-c, grey bars). In contrast, in the absence of wrwycr, we were still able to detect $10^{3}-10^{4}$ c.f.u. $\mathrm{ml}^{-1}$ of each of these strains after 30-120 min of similar acid exposure (Fig. 3a-c, black bars).

\section{Peptide/acid treatment has minimal impact on toxin production}

Finally, we sought to determine whether wrwycr/acid treatment alters the production of active STx. An established quantitative Vero cell assay was used. The results showed little or no significant difference in STx production after wrwycr treatment of strains representing seropathotypes A, B and C. The standard curves for STx1 and STx2 (Fig. 4d) were used to generate $\mathrm{CD}_{50}$ values:
$1.5 \times 10^{-7} \mu \mathrm{g} \mathrm{ml}^{-1}$ for STx1 versus $3 \times 10^{-7} \mu \mathrm{g} \mathrm{ml}^{-1}$ for STx2. Fig. 4 shows the cytoxicity curves for STx periplasmic extracts from strains representing each of the seropathotypes at $\mathrm{pH} 2.5$ with and without wrwycr. Using the $\mathrm{CD}_{50}$ values from the standard curves, we found a minor 2.3-fold increase in the $\mathrm{CD}_{50}$ value for the periplasmic extract from strain 86-24 (seropathotype A) after wrwycr/acid treatment relative to acid treatment alone. Strain CL106 (seropathotype B) and N99-4390 (seropathotype C) showed no change in periplasmic toxin production after peptide treatment (Fig. 4b, c). Secreted STx extracts were similarly tested (results not shown) and we found no change in the $\mathrm{CD}_{50}$ value for strain 86-24 (seropathotype A), a 1.5-fold decrease in the $\mathrm{CD}_{50}$ value for strain CL106 (seropathotype B) and a fivefold increase in the $\mathrm{CD}_{50}$ value for secreted $\mathrm{STx}$ for strain N99-4390 (seropathotype C). These changes are relatively small when compared with studies that report increases in STx production of 13-20-fold with subinhibitory concentrations of the antibiotic fosfomycin (Wolf et al., 1997; Ito et al., 1997), and up to $169-436 \%$ increases in the presence of the antibiotic ciprofloxacin (Walterspiel et al., 1992).

\section{DISCUSSION}

STEC infection is a serious public health concern due to its ability to cause haemorrhagic colitis as well as HUS, the primary cause of paediatric renal failure. Since the strains that are highly associated with human diarrhoeal disease outbreaks and progression to HUS typically belong to seropathotypes A, B and to a lesser extent C (Karmali et al., 2003), strategies to prevent infection with these three
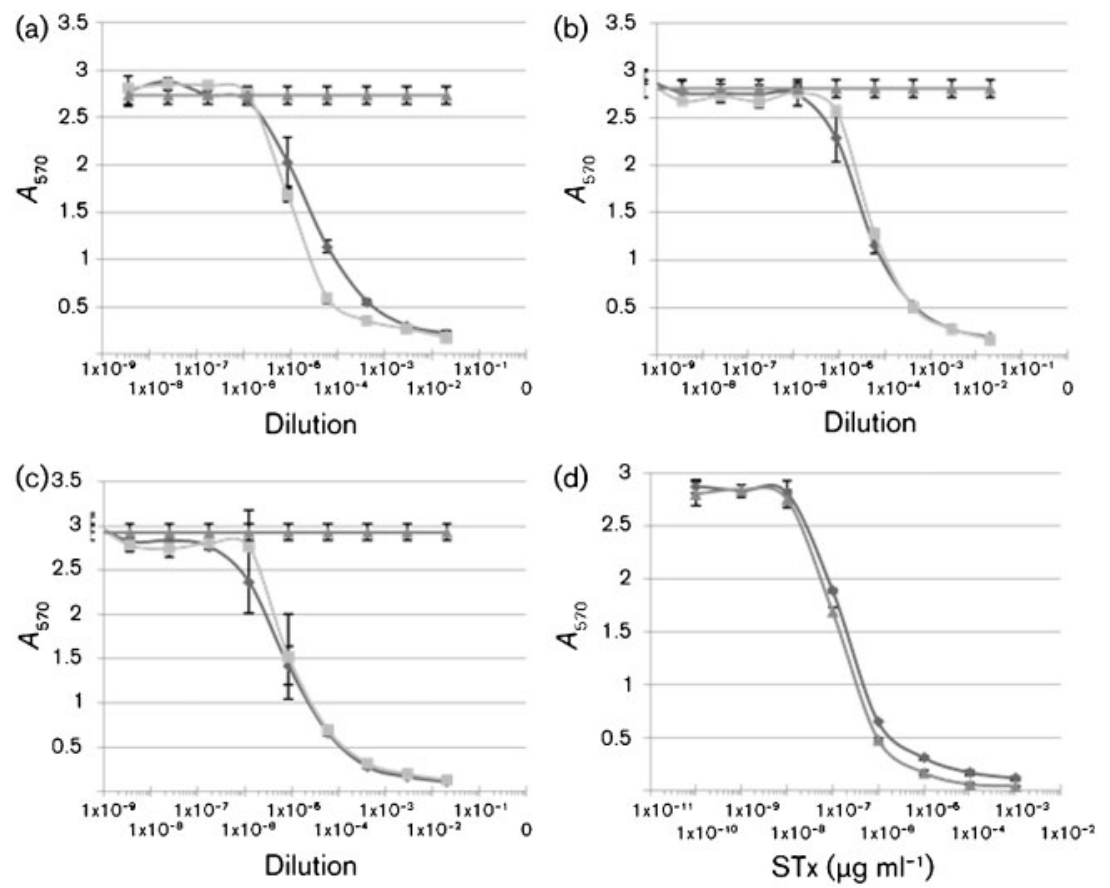

Fig. 4. Effect of wrwycr/acid stress treatment on periplasmic STx production as measured by the Vero cell cytotoxicity assay for STEC strains 86-24 (a), CL106 (b) and N99-4390 (c). Following the indicated treatment, periplasmic extracts were prepared from each strain and diluted serially on Vero cells. After $72 \mathrm{~h}$, adherent, viable cells were stained with crystal violet and absorbance was read at $570 \mathrm{~nm}$. Results are expressed as the mean absorbance $\pm S D$ versus the dilution of extract and are representative of three independent experiments. $\Delta$, Control (no STx); $\diamond, \mathrm{pH} 2.5$; a, $\mathrm{pH} 2.5+25 \mu \mathrm{M}$ wrwycr. Standard curves for STx1 $(\Delta)$ and STx2 $(\Delta)$ are shown in (d). Error bars indicate SD. 
seropathotypes is of critical importance. There has been intense research effort devoted to investigating STEC colonization as well as the subsequent infection and toxin-mediated damage. As a result, we have a comprehensive understanding of the pathogenic mechanism of STEC. Yet, to date, success in developing targeted antimicrobials based on this understanding has been limited. There has been success in developing a bovine vaccine for STEC but there will always remain a need for additional interventions (Withee et al., 2009).

In this paper, we focused on the development of a novel strategy to inhibit STEC survival rather than directly targeting prevention of colonization/infection. Our strategy takes advantage of the natural antimicrobial action of gastric acid stress in a way that prevents the pathogen from recovering from this stress and proceeding to colonize the large intestine. Acid-induced DNA damage triggers repair pathways including recombination repair of DNA lesions and collapsed replication forks, both of which can proceed through HJ intermediates. The hexapeptide used in this study has been shown to bind strongly to $\mathrm{HJ}$ structures and inhibit their resolution; the damage this peptide confers in cells is consistent with inhibition of DNA repair in vivo (Gunderson \& Segall, 2006; Gunderson et al., 2009).

Our results showed that while acid stress alone achieved a significant decrease in survival of strains from all seropathotypes, there were still reasonable levels of survival which varied with the seropathotype. Strains from pathotypes $\mathrm{A}$ and $\mathrm{B}$ were clearly viable after $3 \mathrm{~h}$ at pH 2.5 (2-3 log decrease relative to unstressed). Strains from seropathotype $\mathrm{C}$ were viable and detectable up to $2 \mathrm{~h}$ in $\mathrm{LB}$ at $\mathrm{pH} 2.5$.

In contrast, when acid stress was preceded by a $5 \mathrm{~min}$ treatment with $25 \mu \mathrm{M}$ wrwycr, strains from seropathotypes $\mathrm{A}, \mathrm{B}$ and $\mathrm{C}$ showed significant and dramatic decreases in survival relative to acid stress alone. Survival loss increased significantly with the increased time of acid stress as well as increased treatment temperature or peptide concentration. However, the most dramatic survival loss was achieved with a brief incubation at room temperature with $25 \mu \mathrm{M}$ peptide followed by a $37{ }^{\circ} \mathrm{C}$ treatment at $\mathrm{pH} 2.5$. Using this treatment protocol, there was no detectable survival in any of the strains from seropathotypes A, B or C after 15-60 min of wrwycr/acid treatment. These changes were confirmed for two strains from group A, two from group B and one from group C. These results suggest a dramatic increase in the killing effect of acid stress in the presence of wrwycr for strains from all three seropathotypes associated with severe human disease and outbreaks, underscoring the potential of this approach as a novel antimicrobial strategy. Secondly, the results indicate that peptide/acid treatment is particularly effective with a room temperature peptide incubation followed by $37{ }^{\circ} \mathrm{C}$ incubation with acid, suggesting that the peptide may be effective as a pre-ingestion intervention strategy when coupled with subsequent exposure to acute acid associated with gastric passage.
Antibiotic treatment of STEC infection is contra-indicated in part because studies have shown that there is an elevated risk of progression to HUS in STEC-infected patients treated with certain antibiotics (Dundas et al., 2001; Tarr et al., 2005; Wong et al., 2000). Although it is still unclear how antibiotics increase the risk of HUS, studies have suggested that it may involve induction of the bacteriophages containing the STx genes, thereby increasing production of toxin (Kimmitt et al., 2000). Both epidemiological reports and studies using animal models suggest that the severity of HUS correlates with the amount of STx produced during infection (Dean-Nystrom et al., 2003). Consequently, new antimicrobial treatments for STEC infection should ensure that STx production/release is minimized. We have shown either no or relatively small increases in STx production for strains from any of the pathogenic seropathotypes. These findings stand in stark contrast with the results of studies showing large, significant increases in STx production with subinhibitory concentrations of antibiotics including trimethoprim/ sulfamethoxazole, ciprofloxacin, norfloxacin, fosfomycin and ceftazimidime (Ito et al., 1997; Walterspiel et al., 1992; Wolf et al., 1997).

With no specific therapy or treatment for STEC infection other than intravenous fluids on the horizon, a preinfection intervention for STEC infection could provide a useful strategy. Such a strategy would target STEC prior to colonization and infection and prior to the development of serious Shiga toxin-mediated systemic consequences, a development which cannot be reversed by antibiotic treatment. The finding that wrwycr in combination with acid treatment significantly and profoundly reduces survival of STEC seropathotypes associated with severe human disease provides an exciting new opportunity for envisioning a pre-ingestion antimicrobial treatment for the prevention of STEC infection.

\section{ACKNOWLEDGEMENTS}

This research was supported by a Natural Sciences and Engineering Research Council (NSERC) of Canada Discovery Grant to D. B.F. A. M. S. was supported by NAID grant RO1-058253A1. J. V. K. was supported by an NSERC postdoctoral fellowship and S. L. T. was supported by a postdoctoral fellowship awarded by Ryerson University. We gratefully acknowledge A. Laursen at Ryerson University for his advice and assistance with the statistical analysis.

\section{REFERENCES}

Ake, J. A., Jelacic, S., Ciol, M. A., Watkins, S. L., Murray, K. F., Christie, D. L., Klein, E. J. \& Tarr, P. I. (2005). Relative nephroprotection during Escherichia coli $\mathrm{O} 157$ : H7 infections: association with intravenous volume expansion. Pediatrics 115, e673-e680.

Azaro, M. A. \& Landy, A. (2002). Lambda integrase and the lambda Int family. In Mobile DNA II, pp. 118-148. Edited by N. L. Craig, R. Craigie, M. Gellert \& A. M. Lambowitz. Washington, DC: American Society for Microbiology. 
Banatvala, N., Griffin, P. M., Greene, K. D., Barrett, T. J., Bibb, W. F., Green, J. H., Wells, J. G. \& Hemolytic Uremic Syndrome Study Collaborators (2001). The United States national prospective hemolytic uremic syndrome study: microbiologic, serologic, clinical, and epidemiologic findings. J Infect Dis 183, 1063-1070.

Bavaro, M. F. (2009). Escherichia coli O157: what every internist and gastroenterologist should know. Curr Gastroenterol Rep 11, 301-306.

Boldt, J. L., Pinilla, C. \& Segall, A. M. (2004). Reversible inhibitors of lambda integrase-mediated recombination efficiently trap Holliday junction intermediates and form the basis of a novel assay for junction resolution. J Biol Chem 279, 3472-3483.

Cassell, G., Klemm, M., Pinilla, C. \& Segall, A. (2000). Dissection of bacteriophage lambda site-specific recombination using synthetic peptide combinatorial libraries. J Mol Biol 299, 1193-1202.

Coombes, B. K., Wickham, M. E., Mascarenhas, M., Gruenheid, S., Finlay, B. B. \& Karmali, M. A. (2008). Molecular analysis as an aid to assess the public health risk of non-O157 Shiga toxin-producing Escherichia coli strains. Appl Environ Microbiol 74, 2153-2160.

Cox, M. M., Goodman, M. F., Kreuzer, K. N., Sherratt, D. J., Sandler, S. J. \& Marians, K. J. (2000). The importance of repairing stalled replication forks. Nature 404, 37-41.

Dean-Nystrom, E. A., Melton-Celsa, A. R., Pohlenz, J. F., Moon, H. W. \& O'Brien, A. D. (2003). Comparative pathogenicity of Escherichia coli O157 and intimin-negative non-O157 Shiga toxin-producing $E$ coli strains in neonatal pigs. Infect Immun 71, 6526-6533.

Dundas, S., Todd, W. T., Stewart, A. I., Murdoch, P. S., Chaudhuri, A. K. \& Hutchinson, S. J. (2001). The central Scotland Escherichia coli O157 : H7 outbreak: risk factors for the hemolytic uremic syndrome and death among hospitalized patients. Clin Infect Dis 33, 923-931.

Foster, J. W. (2004). Escherichia coli acid resistance: tales of an amateur acidophile. Nat Rev Microbiol 2, 898-907.

Gentry, M. K. \& Dalrymple, J. M. (1980). Quantitative microtiter cytotoxicity assay for Shigella toxin. J Clin Microbiol 12, 361-366.

Gunderson, C. W. \& Segall, A. M. (2006). DNA repair, a novel antibacterial target: Holliday junction-trapping peptides induce DNA damage and chromosome segregation defects. Mol Microbiol 59, 1129-1148.

Gunderson, C. W., Boldt, J. L., Authement, R. N. \& Segall, A. M. (2009). Peptide wrwycr inhibits the excision of several prophages and traps Holliday junctions inside bacteria. J Bacteriol 191, 2169-2176.

House, B., Kus, J. V., Prayitno, N., Mair, R., Que, L., Chingcuanco, F., Gannon, V., Cvitkovitch, D. G. \& Barnett Foster, D. (2009). Acidstress-induced changes in enterohaemorrhagic Escherichia coli O157 : H7 virulence. Microbiology 155, 2907-2918.

Ito, T., Akino, E. \& Hiramatsu, K. (1997). [Evaluation of antibiotics used for enterohemorrhagic Escherichia coli O157 enteritis - effect of various antibiotics on extracellular release of verotoxin]. Kansenshogaku Zasshi 71, 130-135 (in Japanese).

Karmali, M. A. (2004). Infection by Shiga toxin-producing Escherichia coli: an overview. Mol Biotechnol 26, 117-122.

Karmali, M. A., Petric, M., Lim, C., Cheung, R. \& Arbus, G. S. (1985). Sensitive method for detecting low numbers of verotoxin-producing Escherichia coli in mixed cultures by use of colony sweeps and polymyxin extraction of verotoxin. J Clin Microbiol 22, 614-619.

Karmali, M. A., Mascarenhas, M., Shen, S., Ziebell, K., Johnson, S., Reid-Smith, R., Isaac-Renton, J., Clark, C., Rahn, K. \& Kaper, J. B. (2003). Association of genomic O island 122 of Escherichia coli EDL 933 with verocytotoxin-producing Escherichia coli seropathotypes that are linked to epidemic and/or serious disease. J Clin Microbiol 41, 4930-4940.

Kepple, K. V., Boldt, J. L. \& Segall, A. M. (2005). Holliday junctionbinding peptides inhibit distinct junction-processing enzymes. Proc Natl Acad Sci U S A 102, 6867-6872.

Kepple, K. V., Patel, N., Salamon, P. \& Segall, A. M. (2008). Interactions between branched DNAs and peptide inhibitors of DNA repair. Nucleic Acids Res 36, 5319-5334.

Kimmitt, P. T., Harwood, C. R. \& Barer, M. R. (2000). Toxin gene expression by Shiga toxin-producing Escherichia coli: the role of antibiotics and the bacterial SOS response. Emerg Infect Dis 6, 458465.

Kunkel, T. A. (1984). Mutational specificity of depurination. Proc Natl Acad Sci U S A 81, 1494-1498.

Kuzminov, A. (1999). Recombinational repair of DNA damage in Escherichia coli and bacteriophage lambda. Microbiol Mol Biol Rev 63, 751-813.

Lin, J., Smith, M. P., Chapin, K. C., Baik, H. S., Bennett, G. N. \& Foster, J. W. (1996). Mechanisms of acid resistance in enterohemorrhagic Escherichia coli. Appl Environ Microbiol 62, 3094-3100.

Michel, B., Boubakri, H., Baharoglu, Z., LeMasson, M. \& Lestini, R. (2007). Recombination proteins and rescue of arrested replication forks. DNA Repair (Amst) 6, 967-980.

Nataro, J. P. \& Kaper, J. B. (1998). Diarrheagenic Escherichia coli. Clin Microbiol Rev 11, 142-201.

Palermo, M. S., Exeni, R. A. \& Fernández, G. C. (2009). Hemolytic uremic syndrome: pathogenesis and update of interventions. Expert Rev Anti Infect Ther 7, 697-707.

Scheiring, J., Andreoli, S. P. \& Zimmerhackl, L. B. (2008). Treatment and outcome of Shiga-toxin-associated hemolytic uremic syndrome (HUS). Pediatr Nephrol 23, 1749-1760.

Su, L. Y., Willner, D. L. \& Segall, A. M. (2010). An antimicrobial peptide that targets DNA repair intermediates in vitro inhibits Salmonella growth within murine macrophages. Antimicrob Agents Chemother 54, 1888-1899.

Tarr, P. I., Gordon, C. A. \& Chandler, W. L. (2005). Shiga-toxinproducing Escherichia coli and haemolytic uraemic syndrome. Lancet 365, 1073-1086.

Walterspiel, J. N., Morrow, A. L., Cleary, T. G. \& Ashkenazi, S. (1992). Effect of subinhibitory concentrations of antibiotics on extracellular Shiga-like toxin I. Infection 20, 25-29.

Withee, J., Williams, M., Disney, T., Schlosser, W., Bauer, N. \& Ebel, E. (2009). Streamlined analysis for evaluating the use of preharvest interventions intended to prevent Escherichia coli O157 : H7 illness in humans. Foodborne Pathog Dis 6, 817-825.

Wolf, L. E., Acheson, D. W. K., Lincicome, L. L. \& Kuesch, G. T. (1997). Subinhibitory concentrations of antibiotic increase the release of shiga-like toxin from Escherichia coli O157: H7 in vitro. In Proceedings of the 3rd International Symposium and Workshop on Shiga Toxin (Verotoxin)-Producing Escherichia coli infections, p. 60. Edited by M. A. Karmali. Baltimore: VTEC '97 Committee.

Wong, C. S., Jelacic, S., Habeeb, R. L., Watkins, S. L. \& Tarr, P. I. (2000). The risk of the hemolytic-uremic syndrome after antibiotic treatment of Escherichia coli O157 : H7 infections. N Engl J Med 342, 1930-1936.

Edited by: V. Sperandio 